\title{
The Manganese Influence on the AISi12 Alloy Alfinal Bath Mechanical Properties Change
}

Lubomír Hodinář, Jaroslava Svobodová, Iryna Hren, Jaromír Cais, Štefan Michna

Faculty of Mechanical Engineering, University of J. E. Purkyně in Ústí nad Labem, Pasteurova 7, 40096 Ústí nad Labem. Czech Republic. E-mail: lubomir.hodinar@ujep.cz, jaroslava.svobodova@ujep.cz, iryna.hren@ujep.cz, jaromir.cais@ujep.cz, stefan.michna@ujep.cz

The experiment described in this article deals with the possibility of AISi12 alloy alfinal bath mechanical properties change used in the manufacture of the compression ignition engines pistons by the addition of manganese. The alfinal bath is intended for the aluminium layer deposition which provides more convenient connection of the carrier with the aluminum alloy after casting in the mold. The analysis performed in the experiment were focused on the assessment of the manganese addition influence in the form of the AIMn20 master alloy on the resulting mechanical properties of the AlSi12 alloy in which the iron content gradually changes (up to 7 wt. \%). The iron is released from inserting cast iron rings. The research is primarily focused on assessing of strength and hardness of the alloy which is affected by the occurrence of intermetallic phases excluded in the microstructure depending on the ratio of iron to manganese content. The alloy with the high Fe content was subjected to the static tensile test and Brinell hardnes test measurement after the manganese addition.

Keywords: Alfinal Bath, Intermetallic Phase, Iron, Mangan, Strenght, Hardness

\section{Introduction}

The alloys of the Al-Si type are the representatives of the most used types of foundry alloys. The great variability of the use in this area owes in particular the combination of its suitable mechanical and foundry properties. The castings manufactured from these alloys finding their applications especially in the automotive and aerospace industries. The alloys of this type are predominantly used in the automotive industry for castings of parts of internal combustion engines (cylinder blocks and heads, pistons). The properties of the aluminium alloys Al-Si type are substantially influenced by their chemical composition. The whole rank of additive elements such as $\mathrm{Ni}, \mathrm{Cr}, \mathrm{Mg}$, $\mathrm{Mn}, \mathrm{Zn}$ is known thanks to long-time researches which significantly contribute to the mechanical properties increasing both at normal and elevated temperatures, corrosion resistance etc. The second part of the elements, which have the undesirable influence on the Al-Si alloys properties, are so-called admixtures. Frequent admixture which occurs in the Al-Si alloys is iron. Its presence in $\mathrm{Al}-\mathrm{Si}$ alloys is given especially by the use of the secondary charging raw materials. The proportion of adverse elements in aluminium alloys is due to the perpetually increasing pressure on the the recycling of waste still greater. The possible source of the higher iron content in aluminium alloys can bez the fusion crucible, feeding tube, handling metallic preparations which come into contact with the melt or untreated molds. Already a little iron content in aluminium alloy creates intermetallic phases $-\mathrm{FeAl}_{3}, \mathrm{FeSiAl}_{5}, \mathrm{AlFeSi}$ and others in the form of little plates or plates which in the plane of metallographic sample are displayed as the elongated needles [1 - 3]. These insoluble intermetallic phases have significantly different modulus of elasticity and thermal expansion than aluminium. Therefore, they are used as stress concentrators under mechanical stress. It is thus obvious, that they have a significant impact on the strength properties of Al-Si alloys and in particular adversely affects ductility which decreases with the increasing iron content. Another negative aspect of increased iron content in aluminum alloys is decreasing of its corrosion resistance. To compensate of the adverse effect of iron, the other metals are added to Al-Si alloys: $\mathrm{Mn}, \mathrm{Co}, \mathrm{Cr}$ and Ni. These elements have the ability to bind iron and creates a more favourable intermetallic phases. At present, it is the most widely used iron corrector in aluminum alloys manganese, whose optimal concentration corresponds to one half of the iron concentration in the alloy. Due to the addition of manganese at optimal concentration occurs to the intermetallic $\alpha$-AlFeMnSi phase formation (known as the Chinese font). The adding manganese influence to the resulting intermetallic phase significantly affects the effects of iron [4 - 7].

The article deals with the recycling options of alfinal bath from the AlSi12 alloy through the addition of manganese. This alloy, called alfinal bath with a gradually increasing iron content is formed as one of the waste products in the process of pistons production. The pistons for combustion engines are produced from the Al-Si type alloy. The cast iron carrier of the piston ring is inserted in to the mold for increasing of the pistons strength. The molds are immersed in AlSi12 alloy melt, also referred as an alfinal bath, before the inserting of the piston ring carrier into the metal casting mold. The time for immersion of the piston ring carrier is from 3 to 4 minutes at temperature from $720^{\circ} \mathrm{C}$ to $730^{\circ} \mathrm{C}$. The purpose of alfination is the application of the Al-Si alloy layer on the pistons rings carrier surface (produced from cast iron) and thus ensuring the following better interconnection of the carrier with aluminium alloy (from which the piston is produced) after casting in the mold. The repeated immersion of the pistons rings carriers in alfinal bath causes permanent exclusion of the high iron content during the working process (through its diffusion into the melt). Increasing iron content in this bath reduces its useful life for immersion of the others carriers. After the prescribed period of time, for which the carrier is in the alfinal bath, it is inserted 
into the mold using the slide tongs.

The mold is closed and the aluminum alloy for pistons productinon is poured into it after inserting the carrier. After solidification of aluminum alloy and interconnection of the cast iron carrier in the piston casting, the raw casting is removed. The criterion for exchange of the alfinal bath is the iron content in the alloy corresponding to 6 wt. \%. Exceeding this iron content leads to the devaluation of the alfinal bath and subsequent replacement for a new one.

\section{Experiment Description}

The aim of the experiment described in this article was to assess the effect of manganese addition on the AlSi12 alloy (alfinal bath) with the content 5 wt. \% - 7 wt. $\%$ of iron to the resulting microstructure, in particular the elongation, strength and hardness of the alloy. The chemical composition of the alfinal bath, which served as the basis for subsequent melting and alloying with manganese, is shown in the table 1 . The chemical composition was analyzed using the Q4 TASMAN optical emission spectrometer (the Innov X Delta portable X-ray spectrometer was also used to verify the results). The contents of the individual elements are in the tab. 1 (the average values of ten measurements).

Sample melting was performed in an electric resistance furnace at $780{ }^{\circ} \mathrm{C}$. The charge of 2000 grams weight was prepared in the tough graphite crucibles. Four charges were generally created. After the charge was melted, this melt was alloyed by manganese and there was prepared four variants: alfinal bath without the addition of manganese, alfinal bath with the addition of 1,2 and 3 wt. \% of manganese in the melt. Alloing of the alfinal bath to the desired manganese content in the melt was performed by adding of the master alloy AlMn20. After re-returning of the crucibles to the furnace and melting the alloy (for about 30 minutes), the casting was performed at $760{ }^{\circ} \mathrm{C}$. Casting was carried out in a preheated metal mold (at $200{ }^{\circ} \mathrm{C}$ ). The resulting castings were cylindrical with a diameter of about $19 \mathrm{~mm}$ and a length of $210 \mathrm{~mm}$ and became the basis for subsequent microstructure analysis and measurement of mechanical properties.

\section{Tab. 1 Chemical composition of the alfinal bath}

\begin{tabular}{|c|c|c|c|c|c|c|c|}
\hline Chemical element & $\mathrm{Si}$ & $\mathrm{Fe}$ & $\mathrm{Cu}$ & $\mathrm{Mn}$ & $\mathrm{Ni}$ & $\mathrm{Cr}$ & $\mathrm{Al}$ \\
\hline Content [wt. \%] & 12.48 & 5.960 & 0.24 & 0.044 & 0.501 & 0.045 & Residue \\
\hline
\end{tabular}

\section{Optical Microscopy}

The metallographic samples made from the central part of the cylindrical specimens cast into a metal mold were used for the analysis of the microstructure. The confocal laser microscope Olympus LEXT OLS 3100 was used for microstructure analysis from the point of view of the character of the excluded intermetallic phases and the changes induced by the addition of manganese in the alfinal bath. The figures of the microstructure created using the confocal laser microscope are denoted as Fig. $1-4$. Fig. 1 (sample of alfination bath without manganese addition), in this figure the microstructure is eutectic. The needle-shaped formations of intermetallic phases with

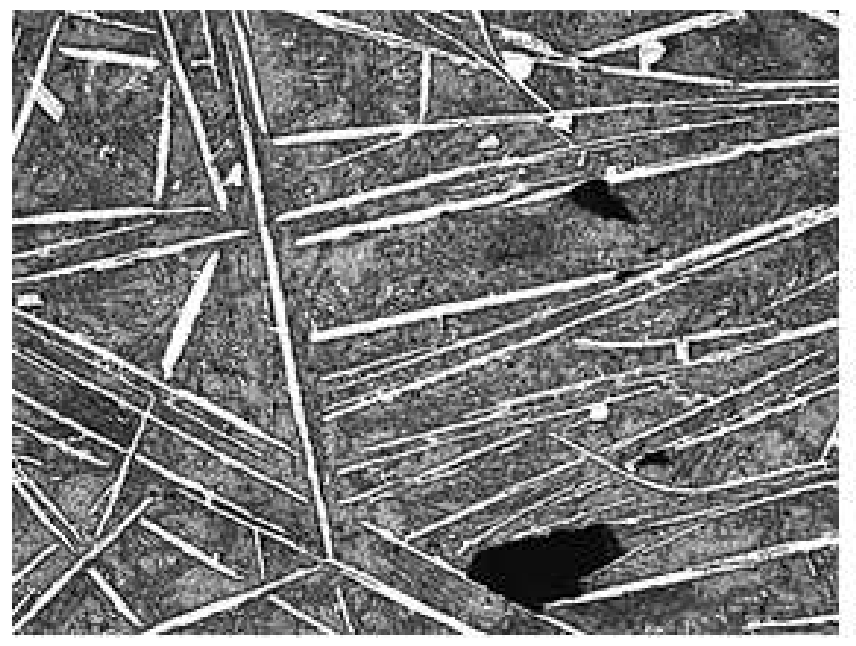

high iron content $-\mathrm{Al}_{5} \mathrm{FeSi}$ are excluded in the microstructure. The microstructure of the sample is created also with eutectic in Fig. 2. The disappearance of the needleshaped intermetallic phases with a high iron content (intermetallic phase $\mathrm{Al}_{5} \mathrm{FeSi}$ ) can be observed in the microstructure and also the increase of the polycomponent intermetallic phases of the Al-Si-Fe-Mn type (sample with 1 wt. \% Mn). Fig. 3 (sample with 2 wt. \% Mn) and Fig. 4 (sample with 3 wt. \% Mn) show a microstructure which is again created by eutectic. Observation of samples with 2 wt. $\%$ and 3 wt. $\%$ of manganese reveals the gradual almost complete conversion of needle-shaped intermetallic $\left(\mathrm{Al}_{5} \mathrm{FeSi}\right)$ formations into the globulitic-shaped intermetallic intermetallic phases Al-Si-Fe-Mn contained in the microstructure.

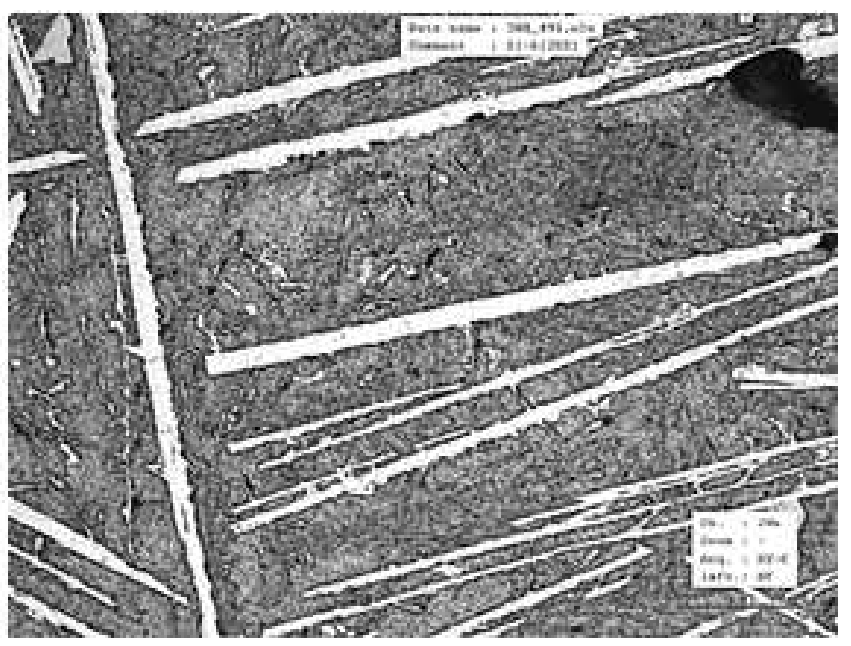

Fig. 1 Alfinal bath without addition of Mn 

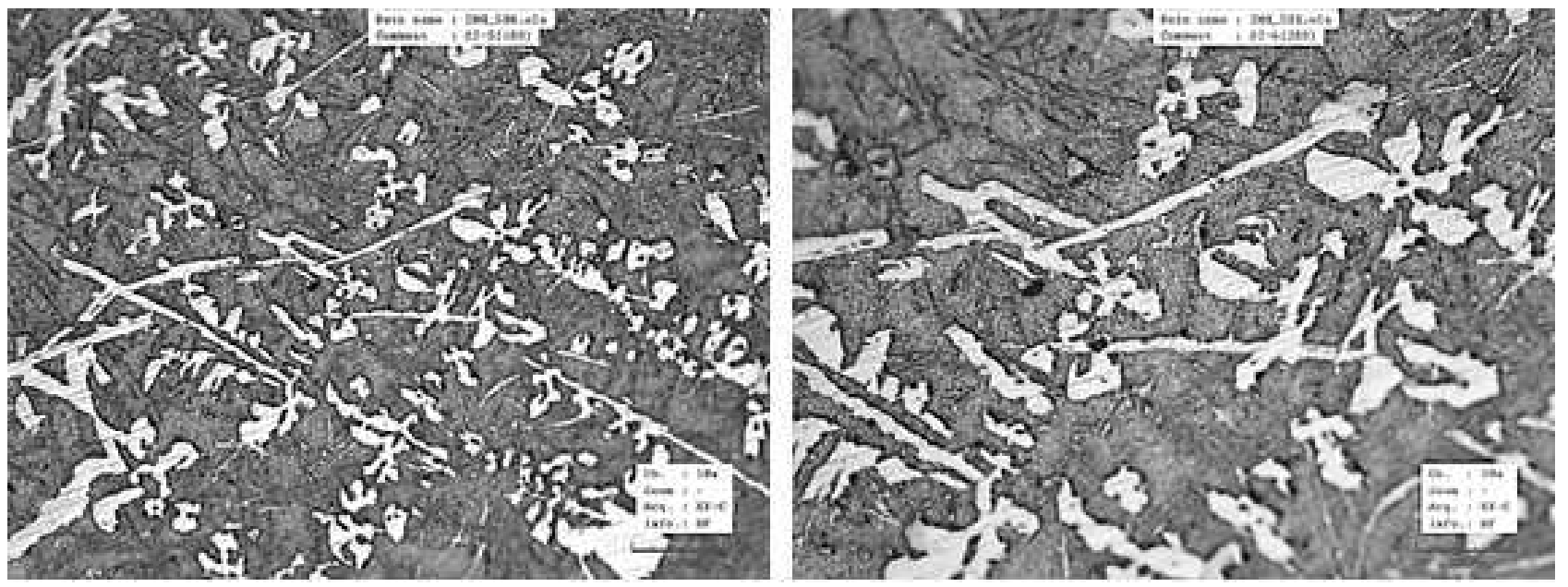

Fig. 2 Alfinal bath with addition of 1 wt. \% of $M n$
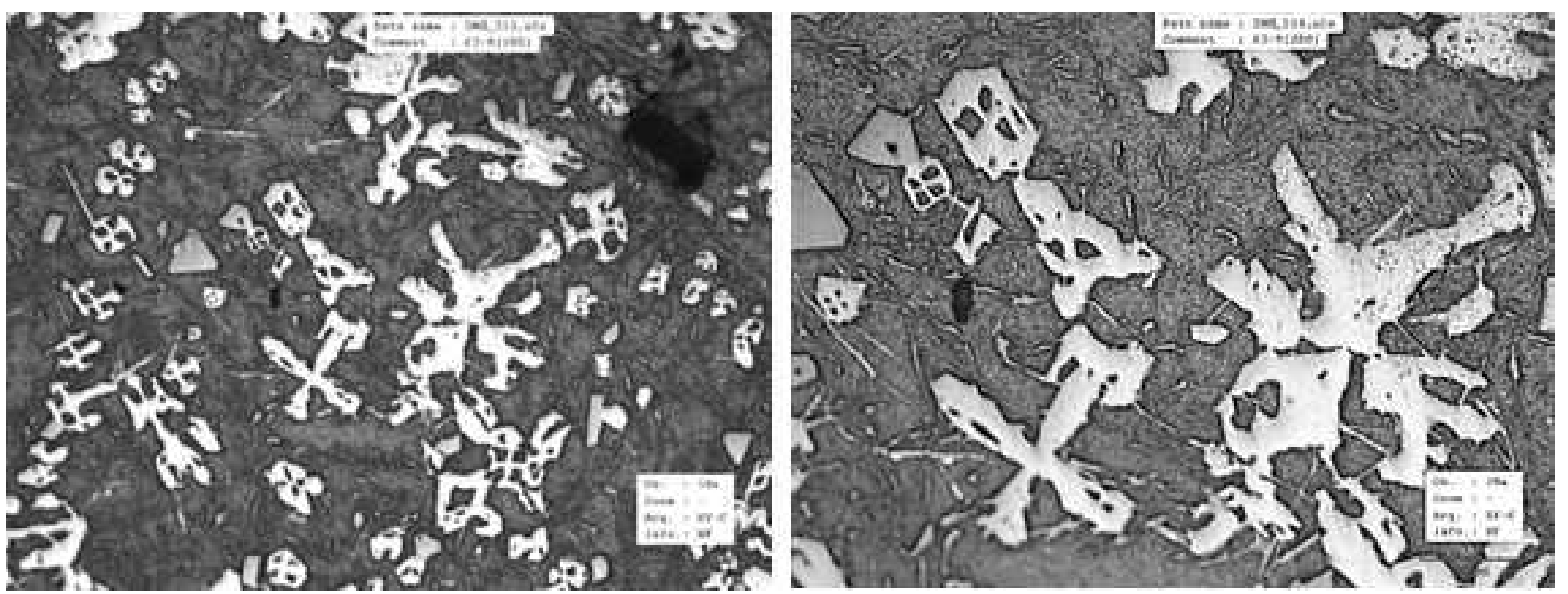

Fig. 3 Alfinal bath with addition of 2 wt. \% of $M n$
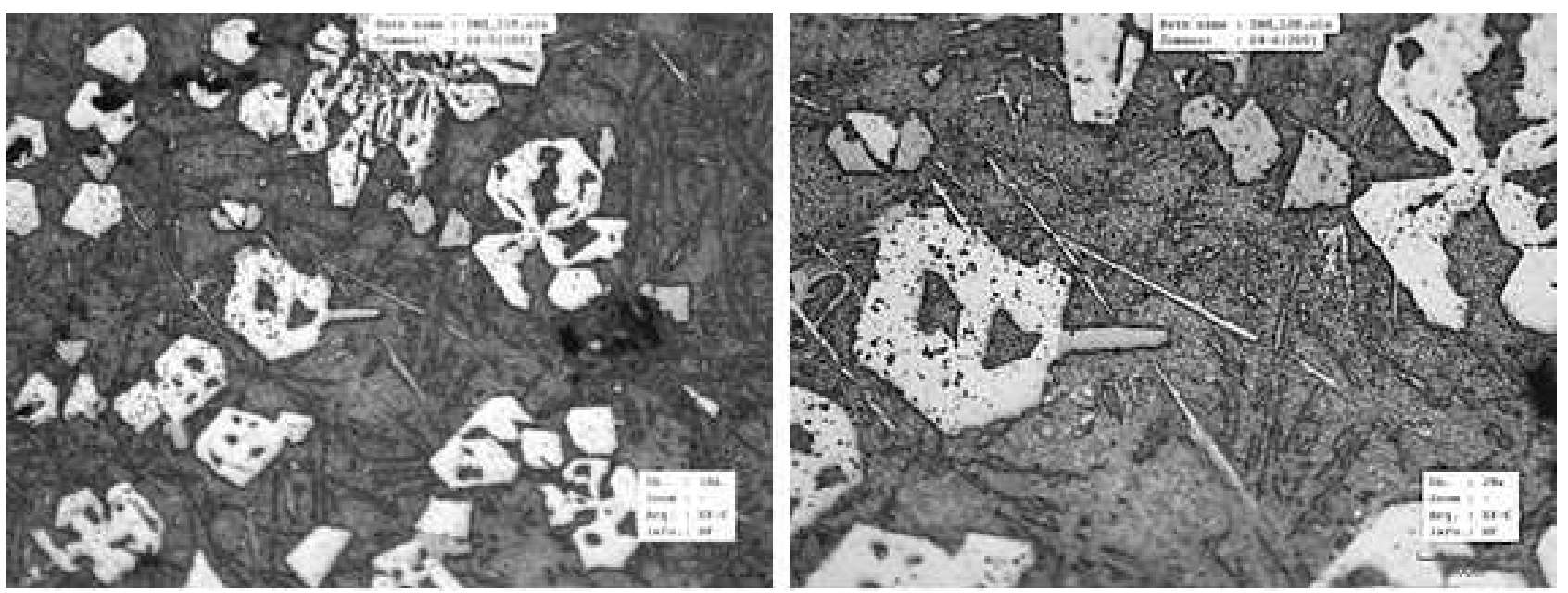

Fig. 4 Alfinal bath with addition of 3 wt. \% of Mn

\section{Static Tensile Test}

In the second stage of the examination, the test samples (according to ČSN EN ISO 6892-1) were cast and machined from AlSi12Fe6 alloy (alfinal bath) in four variants: the test samples A - do not contain manganese addition, the test samples B - contain 1 wt. \% of manganese, test samples $\mathrm{C}$ - contain 2 wt. \% of manganese and test samples D - are made up of 3 wt. \% manganese. The test samples were subjected to a static tensile test on the Inspekt 100 Hegewald \& Peschke universal tearing machine. The results of the static tensile test, including the average values, are shown in tab. 2 .

The sample is subjected to tensile deformation in the tensile test, the size of this deformation increases steadily over time (the deformation rate is constant). Fig. 5 shows 
the results of the static tensile test on the samples 1 which do not contain the addition of manganese. The test was performed at an even load from zero to $55 \mathrm{MPa}$ and the relative elongation converged to $1.7 \%$. The structure of the test sample did not allow a higher load and greater prolongation.

Tab. 2 Static tensile test results

\begin{tabular}{|c|c|c|c|c|c|c|c|c|c|c|}
\hline Name & \multicolumn{3}{|c|}{ Rm [MPa] } & $\varnothing$ Rm [MPa] & \multicolumn{3}{c|}{ A [\%] } & $\varnothing$ A [\%] \\
\hline Sample No. A & 57.262 & 48.179 & 48.235 & - & 51.225 & 1.748 & 1.335 & 1.948 & - & 1.677 \\
\hline Sample No. B & 51.038 & 113.00 & 82.888 & 69.908 & 79.209 & 1.325 & 2.374 & 1.826 & 1.835 & 1.840 \\
\hline Sample No. C & 87.051 & 92.513 & 95.492 & 120.485 & 98.885 & 1.957 & 2.153 & 2.007 & 2.630 & 2.187 \\
\hline Sample No. D & 91.35 & 118.92 & 95.544 & 115.722 & 105.385 & 2.186 & 2.592 & 2.295 & 2.619 & 2.423 \\
\hline
\end{tabular}

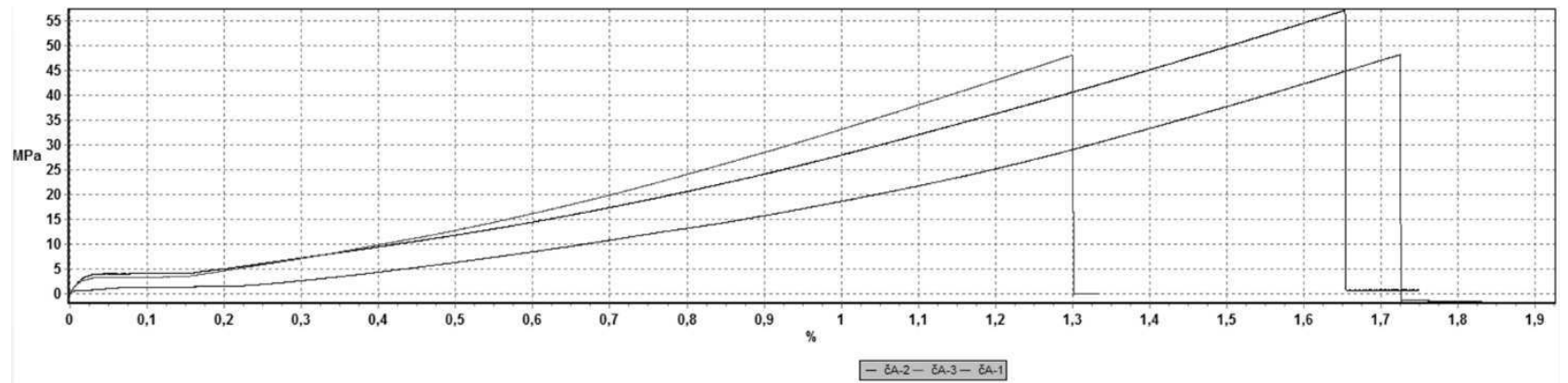

Fig. 5 Static tensile test of the alloy without manganese addition

Due to the addition of manganese in sample No. 2 (alloy containing $1 \mathrm{wt}$ \% of manganese) its plasticity increased, therefore a higher load was used. The sample load reached $110 \mathrm{MPa}$ and the elongation exceeded $1.8 \%$.
It is obvious that the presence of 1 wt. \% of manganese in the alloy allows to increase the load of the examined sample. The results are shown in the graph (Fig. 6).

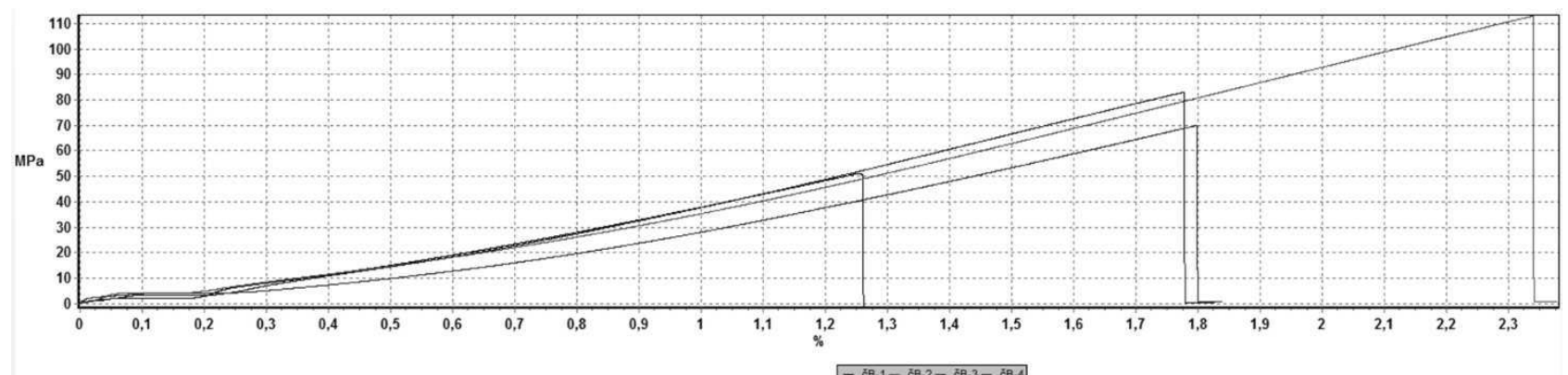

Fig. 6 Static tensile test of the alloy with 1 wt. \% of manganese addition

Static tensile tests for an alloy containing $2 \mathrm{wt}$. \% of manganese (Fig. 7) and an alloy containing $3 \mathrm{wt} . \%$ of manganese (Fig. 8) are shown in the following charts.
Both graphs with the same load (110 MPa) show a partial increase in the relative elongation, ranging from 2.2 to $2.4 \%$.

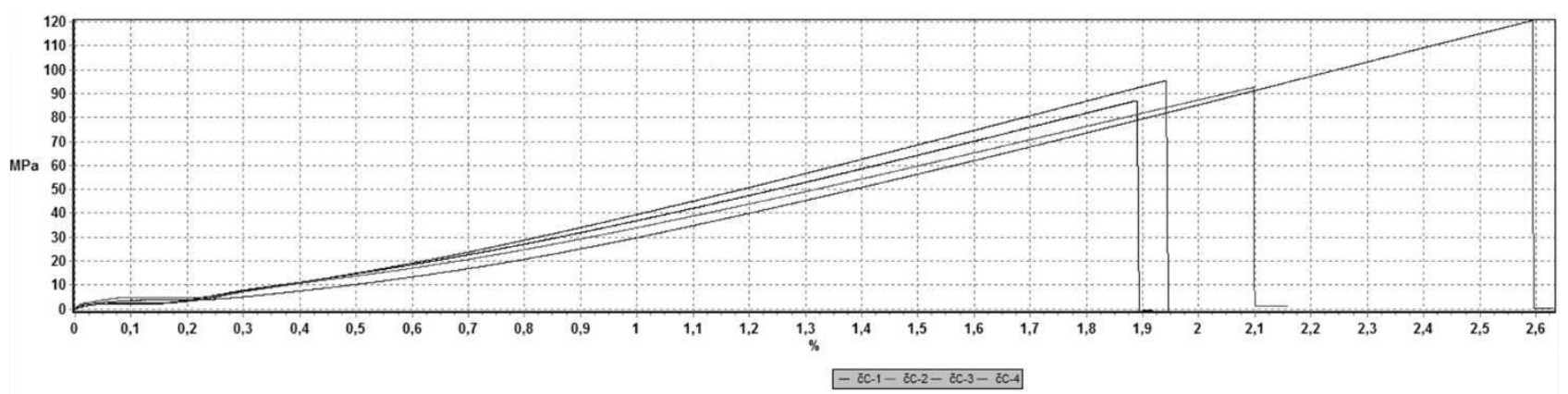

Fig. 7 Static tensile test of alloy with 2 wt. \% of manganese addition 


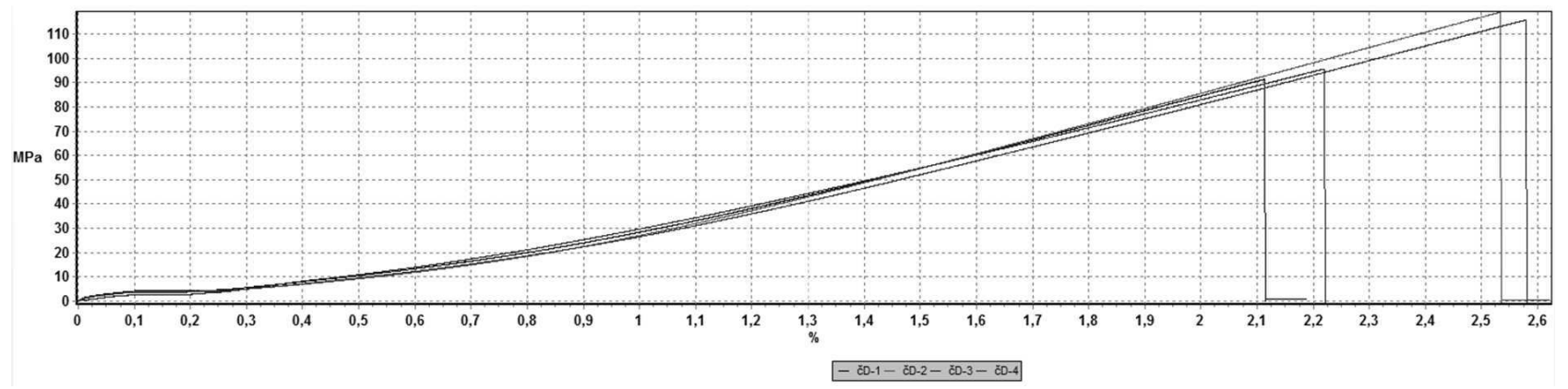

Fig. 8 Static tensile test of alloy with 3 wt. \% of manganese addition

\section{Brinell Hardness Test}

The alfination bath samples of AlSi12Fe6 alloy were subjected to a Brinell hardness test at a load of $62.5 \mathrm{~kg}$ spherical shaped indenter of $2.5 \mathrm{~mm}$ diameter. Ten measurements were performed on each sample. The test was performed on samples No. 1, 2, 3, 4 - on sample No. 1 without addition of manganese, sample No. 2 with the addition of manganese containing 1 wt. \%, sample No. 3 with the addition of 2 wt. \% manganese and sample No. 4 by adding $4 \%$ of manganese content. The measurement results were recorded in tab. 3 .

Tab. 3 Brinell hardness measurement results

\begin{tabular}{|c|c|c|c|c|c|c|c|c|c|c|}
\hline Sample & \multicolumn{10}{|c|}{ Hardness HB } \\
\hline с̌. $\mathbf{1}$ & 102 & 105 & 105 & 108 & 110 & 112 & 107 & 111 & 100 & 109 \\
\hline с̌. $\mathbf{2}$ & 98 & 93 & 95 & 99 & 97 & 97 & 96 & 98 & 97 & 95 \\
\hline с̌. 3 & 99 & 93 & 99 & 98 & 96 & 95 & 95 & 96 & 93 & 92 \\
\hline с.. 4 & 94 & 96 & 95 & 96 & 93 & 98 & 96 & 87 & 91 & 97 \\
\hline
\end{tabular}

The Brinell hardness results listed in Table 2 were processed using static expression (Anova's one factor). Using the statistical expression, the averages and variance of the measurements were calculated. In the experiment, we monitor the effect of one condition (factor-addition of the ligand binding element) that is exposed to three groups of samples tested against the base sample. Statistical analysis is carried out to obtain information as to whether there are differences between groups, we need to compare their diameters to each other for all possible pairs. The statistical comparison shows the significance of the influence of the added element (manganese) on the examined mechanical properties of the samples.

The results of the statistical expression are shown in the following Table 4 - 16 and Fig. 9 - 14, the comments are located below it.

Tab. 4 Statistical expression ANOVA: one factor

\begin{tabular}{|c|c|c|c|c|c|c|c|}
\hline \multicolumn{8}{|c|}{ Summary statistics (Quantitative data): } \\
\hline Variable & $\begin{array}{l}\text { Observati- } \\
\text { ons }\end{array}$ & $\begin{array}{l}\text { Obs. with missing } \\
\text { data }\end{array}$ & $\begin{array}{c}\text { Obs. } \\
\text { without } \\
\text { missing } \\
\text { data }\end{array}$ & $\begin{array}{c}\text { Mi- } \\
\text { nimum }\end{array}$ & Maximum & Mean & $\begin{array}{l}\text { Std. devia- } \\
\text { tion }\end{array}$ \\
\hline Hardness HB & 40 & 0 & 40 & 87.000 & 112.000 & 98.325 & 5.824 \\
\hline
\end{tabular}

Tab. 5 Summary statistics

Summary statistics (Qualitative data):

\begin{tabular}{|c|c|c|c|c|}
\hline Variable & Categories & Counts & Frequencies & \% \\
\hline \multirow{4}{*}{ Sample } & No. 1 & 10 & 10 & 25.000 \\
\cline { 2 - 5 } & No. 2 & 10 & 10 & 25.000 \\
\cline { 2 - 5 } & No. 3 & 10 & 10 & 25.000 \\
\cline { 2 - 5 } & No. 4 & 10 & 10 & 25.000 \\
\hline
\end{tabular}

Tab. 6 Summary statistics

\begin{tabular}{|c|c|c|c|c|c|}
\hline \multicolumn{7}{|l|}{ Correlation matrix: } \\
\hline & Sample - No. 1 & Sample - No. 2 & Sample - No. 3 & Sample - No. 4 & Hardness HB \\
\hline Sample - No. 1 & 1 & -0.333 & -0.333 & -0.333 & 0.861 \\
\hline Sample - No. 2 & -0.333 & 1 & -0.333 & -0.333 & -0.183 \\
\hline Sample - No. 3 & -0.333 & -0.333 & 1 & -0.333 & -0.274 \\
\hline Sample - No. 4 & -0.333 & -0.333 & -0.333 & 1 & -0.404 \\
\hline Hardness HB & 0.861 & -0.183 & -0.274 & -0.404 & 1 \\
\hline
\end{tabular}


Tab. 7 Regression of variable Hardness $H B$

Regression of variable Hardness HB:

Goodness of fit statistics (Hardness HB):

\begin{tabular}{|c|c|}
\hline Observations & 40.000 \\
\hline Sum of weights & 40.000 \\
\hline DF & 36.000 \\
\hline R2 & 0.760 \\
\hline Adjusted R2 & 0.740 \\
\hline MSE & 8.831 \\
\hline RMSE & 2.972 \\
\hline MAPE & 2.282 \\
\hline DW & 1.979 \\
\hline Cp & 4.000 \\
\hline AIC & 90.914 \\
\hline SBC & 97.670 \\
\hline PC & 0.294 \\
\hline
\end{tabular}

Tab. 8 Analysis of variance

\begin{tabular}{|c|c|c|c|c|c|}
\hline Analysis of variance (Hardness HB): \\
\hline Source & DF & Sum of squares & Mean squares & F & Pr $>$ F \\
\hline Model & 3 & 1004.875 & 334.958 & 37.932 & $<0.0001$ \\
\hline Error & 36 & 317.900 & 8.831 & & \\
\hline Corrected Total & 39 & 1322.775 & & & \\
\hline Computed against model $Y=$ Mean $(Y)$ &
\end{tabular}

Tab. 9 Model parameters

Model parameters (Hardness HB):

\begin{tabular}{|c|c|c|c|c|c|c|}
\hline Source & Value & Standard error & $\mathbf{t}$ & $\operatorname{Pr}>|\mathbf{t}|$ & Lower bound (95\%) & Upper bound (95\%) \\
\hline Intercept & 106.900 & 0.940 & 113.758 & $<0.0001$ & 104.994 & 108.806 \\
\hline Sample-No.1 & 0.000 & 0.000 & & & & \\
\hline Sample-No.2 & -10.400 & 1.329 & -7.826 & $<0.0001$ & -13.095 & -7.705 \\
\hline Sample-No.3 & -11.300 & 1.329 & -8.503 & $<0.0001$ & -13.995 & -8.605 \\
\hline Sample-No.4 & -12.600 & 1.329 & -9.481 & $<0.0001$ & -15.295 & -9.905 \\
\hline
\end{tabular}

Tab. 10 Standardized coefficients

Equation of the model (Hardness HB):

Hardness HB = 106,9-10,4*Sample No. 2-11,3*Sample No3-12,6*Sample No. 4

Standardized coefficients (Hardness HB):

\begin{tabular}{|c|c|c|c|c|c|c|}
\hline Source & Value & Standard error & $\mathbf{t}$ & $\operatorname{Pr}>|\mathbf{t}|$ & Lower bound (95\%) & Upper bound (95\%) \\
\hline Sample-No.1 & 0.000 & 0.000 & & & & \\
\hline Sample-No.2 & -0.783 & 0.100 & -7.826 & $<0.0001$ & -0.986 & -0.580 \\
\hline Sample-No.3 & -0.851 & 0.100 & -8.503 & $<0.0001$ & -1.054 & -0.648 \\
\hline Sample-No.4 & -0.949 & 0.100 & -9.481 & $<0.0001$ & -1.152 & -0.746 \\
\hline
\end{tabular}


Tab. 11 Predictions and residuals (Hardness HB)

\begin{tabular}{|c|c|c|c|c|c|c|c|c|c|c|c|}
\hline \multicolumn{12}{|c|}{ Predictions and residuals (Hardness HB): } \\
\hline 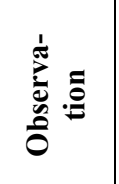 & $\begin{array}{l}\vec{E} \\
\frac{500}{0} \\
\overrightarrow{0}\end{array}$ & 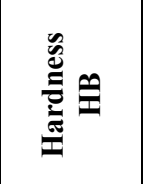 & 总珶泀 & 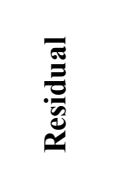 & 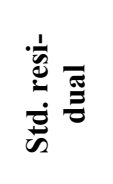 & 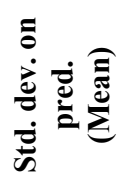 & 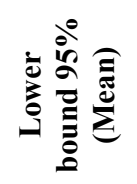 & 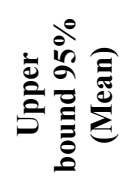 & 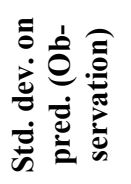 & 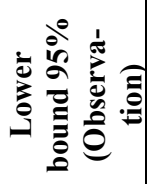 & 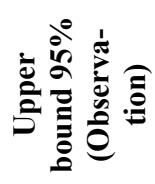 \\
\hline Obs1 & 1 & 102.000 & 106.900 & -4.900 & -1.649 & 0.940 & 104.994 & 108.806 & 3.117 & 100.579 & 113.221 \\
\hline Obs2 & 1 & 105.000 & 106.900 & -1.900 & -0.639 & 0.940 & 104.994 & 108.806 & 3.117 & 100.579 & 113.221 \\
\hline Obs3 & 1 & 105.000 & 106.900 & -1.900 & -0.639 & 0.940 & 104.994 & 108.806 & 3.117 & 100.579 & 113.221 \\
\hline Obs4 & 1 & 108.000 & 106.900 & 1.100 & 0.370 & 0.940 & 104.994 & 108.806 & 3.117 & 100.579 & 113.221 \\
\hline Obs5 & 1 & 110.000 & 106.900 & 3.100 & 1.043 & 0.940 & 104.994 & 108.806 & 3.117 & 100.579 & 113.221 \\
\hline Obs6 & 1 & 112.000 & 106.900 & 5.100 & 1.716 & 0.940 & 104.994 & 108.806 & 3.117 & 100.579 & 113.221 \\
\hline Obs7 & 1 & 107.000 & 106.900 & 0.100 & 0.034 & 0.940 & 104.994 & 108.806 & 3.117 & 100.579 & 113.221 \\
\hline Obs8 & 1 & 111.000 & 106.900 & 4.100 & 1.380 & 0.940 & 104.994 & 108.806 & 3.117 & 100.579 & 113.221 \\
\hline Obs9 & 1 & 100.000 & 106.900 & -6.900 & -2.322 & 0.940 & 104.994 & 108.806 & 3.117 & 100.579 & 113.221 \\
\hline Obs 10 & 1 & 109.000 & 106.900 & 2.100 & 0.707 & 0.940 & 104.994 & 108.806 & 3.117 & 100.579 & 113.221 \\
\hline Obs11 & 1 & 98.000 & 96.500 & 1.500 & 0.505 & 0.940 & 94.594 & 98.406 & 3.117 & 90.179 & 102.821 \\
\hline Obs 12 & 1 & 93.000 & 96.500 & -3.500 & -1.178 & 0.940 & 94.594 & 98.406 & 3.117 & 90.179 & 102.821 \\
\hline Obs 13 & 1 & 95.000 & 96.500 & -1.500 & -0.505 & 0.940 & 94.594 & 98.406 & 3.117 & 90.179 & 102.821 \\
\hline Obs 14 & 1 & 99.000 & 96.500 & 2.500 & 0.841 & 0.940 & 94.594 & 98.406 & 3.117 & 90.179 & 102.821 \\
\hline Obs 15 & 1 & 97.000 & 96.500 & 0.500 & 0.168 & 0.940 & 94.594 & 98.406 & 3.117 & 90.179 & 102.821 \\
\hline Obs16 & 1 & 97.000 & 96.500 & 0.500 & 0.168 & 0.940 & 94.594 & 98.406 & 3.117 & 90.179 & 102.821 \\
\hline Obs 17 & 1 & 96.000 & 96.500 & -0.500 & -0.168 & 0.940 & 94.594 & 98.406 & 3.117 & 90.179 & 102.821 \\
\hline Obs 18 & 1 & 98.000 & 96.500 & 1.500 & 0.505 & 0.940 & 94.594 & 98.406 & 3.117 & 90.179 & 102.821 \\
\hline Obs19 & 1 & 97.000 & 96.500 & 0.500 & 0.168 & 0.940 & 94.594 & 98.406 & 3.117 & 90.179 & 102.821 \\
\hline Obs20 & 1 & 95.000 & 96.500 & -1.500 & -0.505 & 0.940 & 94.594 & 98.406 & 3.117 & 90.179 & 102.821 \\
\hline Obs21 & 1 & 99.000 & 95.600 & 3.400 & 1.144 & 0.940 & 93.694 & 97.506 & 3.117 & 89.279 & 101.921 \\
\hline Obs22 & 1 & 93.000 & 95.600 & -2.600 & -0.875 & 0.940 & 93.694 & 97.506 & 3.117 & 89.279 & 101.921 \\
\hline Obs23 & 1 & 99.000 & 95.600 & 3.400 & 1.144 & 0.940 & 93.694 & 97.506 & 3.117 & 89.279 & 101.921 \\
\hline Obs24 & 1 & 98.000 & 95.600 & 2.400 & 0.808 & 0.940 & 93.694 & 97.506 & 3.117 & 89.279 & 101.921 \\
\hline Obs25 & 1 & 96.000 & 95.600 & 0.400 & 0.135 & 0.940 & 93.694 & 97.506 & 3.117 & 89.279 & 101.921 \\
\hline Obs26 & 1 & 95.000 & 95.600 & -0.600 & -0.202 & 0.940 & 93.694 & 97.506 & 3.117 & 89.279 & 101.921 \\
\hline Obs27 & 1 & 95.000 & 95.600 & -0.600 & -0.202 & 0.940 & 93.694 & 97.506 & 3.117 & 89.279 & 101.921 \\
\hline Obs28 & 1 & 96.000 & 95.600 & 0.400 & 0.135 & 0.940 & 93.694 & 97.506 & 3.117 & 89.279 & 101.921 \\
\hline Obs29 & 1 & 93.000 & 95.600 & -2.600 & -0.875 & 0.940 & 93.694 & 97.506 & 3.117 & 89.279 & 101.921 \\
\hline Obs30 & 1 & 92.000 & 95.600 & -3.600 & -1.211 & 0.940 & 93.694 & 97.506 & 3.117 & 89.279 & 101.921 \\
\hline Obs31 & 1 & 94.000 & 94.300 & -0.300 & -0.101 & 0.940 & 92.394 & 96.206 & 3.117 & 87.979 & 100.621 \\
\hline Obs 32 & 1 & 96.000 & 94.300 & 1.700 & 0.572 & 0.940 & 92.394 & 96.206 & 3.117 & 87.979 & 100.621 \\
\hline Obs33 & 1 & 95.000 & 94.300 & 0.700 & 0.236 & 0.940 & 92.394 & 96.206 & 3.117 & 87.979 & 100.621 \\
\hline Obs34 & 1 & 96.000 & 94.300 & 1.700 & 0.572 & 0.940 & 92.394 & 96.206 & 3.117 & 87.979 & 100.621 \\
\hline Obs35 & 1 & 93.000 & 94.300 & -1.300 & -0.437 & 0.940 & 92.394 & 96.206 & 3.117 & 87.979 & 100.621 \\
\hline Obs36 & 1 & 98.000 & 94.300 & 3.700 & 1.245 & 0.940 & 92.394 & 96.206 & 3.117 & 87.979 & 100.621 \\
\hline Obs37 & 1 & 96.000 & 94.300 & 1.700 & 0.572 & 0.940 & 92.394 & 96.206 & 3.117 & 87.979 & 100.621 \\
\hline Obs38 & 1 & 87.000 & 94.300 & -7.300 & -2.457 & 0.940 & 92.394 & 96.206 & 3.117 & 87.979 & 100.621 \\
\hline Obs39 & 1 & 91.000 & 94.300 & -3.300 & -1.111 & 0.940 & 92.394 & 96.206 & 3.117 & 87.979 & 100.621 \\
\hline Obs40 & 1 & 97.000 & 94.300 & 2.700 & 0.909 & 0.940 & 92.394 & 96.206 & 3.117 & 87.979 & 100.621 \\
\hline
\end{tabular}


Hardness HB / Standardized coefficients ( $95 \%$ conf. interval)

Sample-No. 1

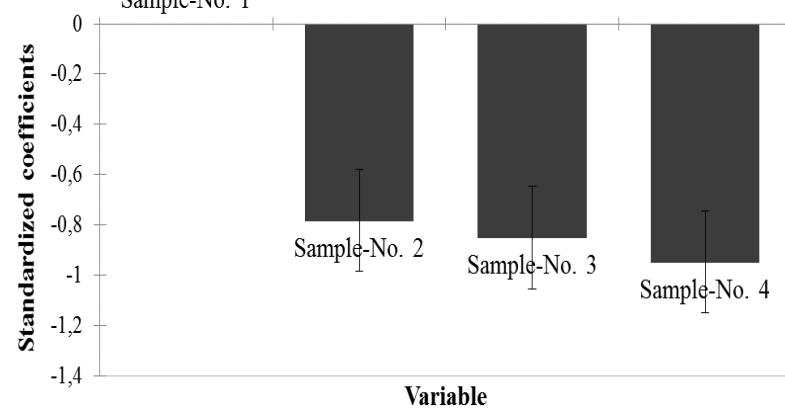

Fig. 8 Hardness HB / Standardized coefficients $(95 \%$ conf. interval)

Hardness HB / Standardized residuals

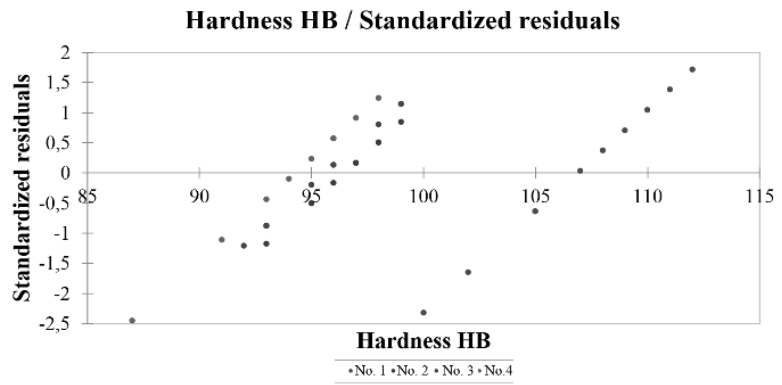

Fig. 9 Hardness HB / Standardized residuals

Pred(Hardness HB) / Standardized residuals

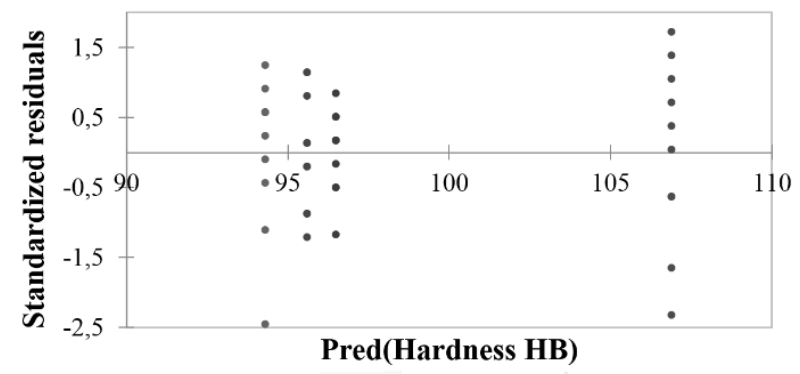

$\cdot$ No. $1 \cdot$ No. $2 \cdot$ №. $3 \cdot$ No. 4

Fig. 10 Pred (Hardness HB) / Standardized residuals

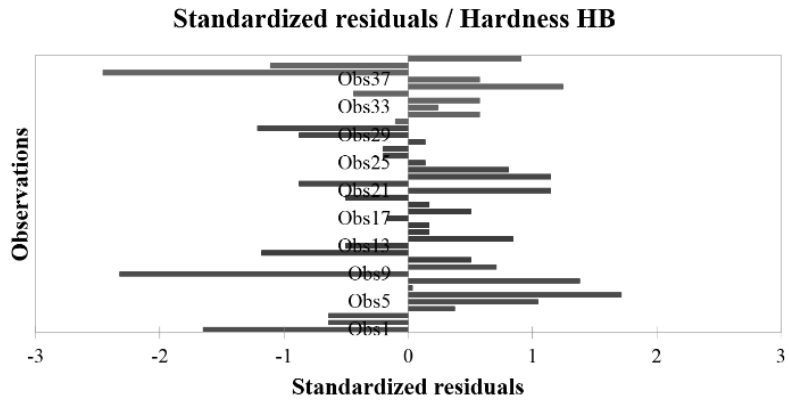

Fig. 11 Standardized residuals / Hardness HB

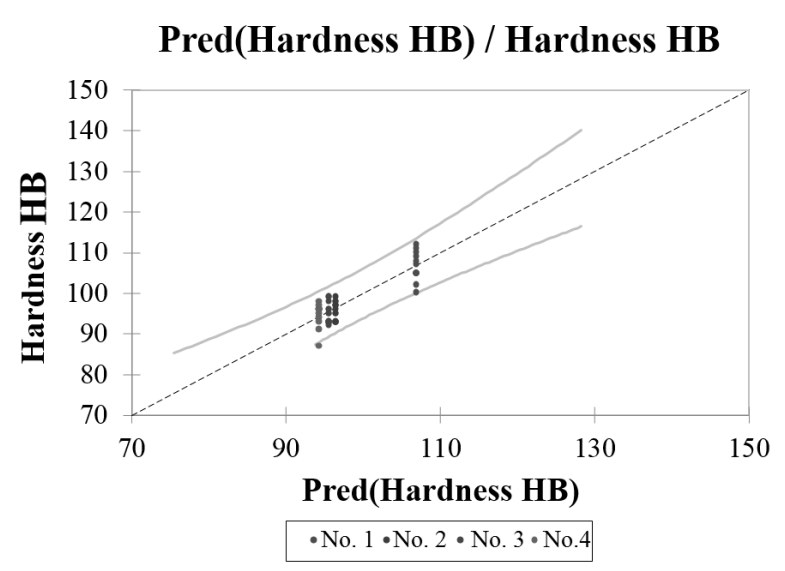

Fig. 12 Pred(Hardness HB) / Hardness HB

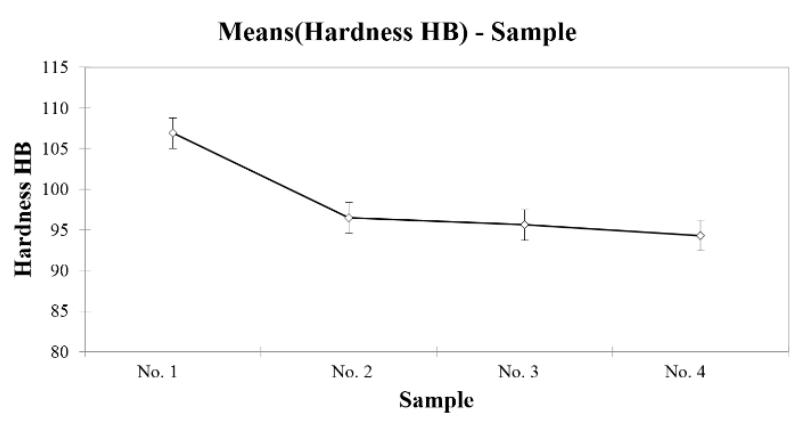

Fig. 13 Means(Hardness HB) / Hardness HB

Tab. 12 Analysis of the differences between the categories with a confidence interval of 95\% (Hardness HB)

\begin{tabular}{|c|c|c|c|c|c|c|}
\hline \multicolumn{7}{|c|}{$\begin{array}{l}\text { Sample / REGWQ / Analysis of the differences between the categories with a confidence interval of } 95 \% \text { (Hard- } \\
\text { ness HB): }\end{array}$} \\
\hline \multicolumn{7}{|c|}{\begin{tabular}{|c|c|c|c|c|c|c} 
Contrast & $\begin{array}{l}\text { Diffe- } \\
\text { rence }\end{array}$ & Standardized difference & $\begin{array}{c}\text { Critical va- } \\
\text { lue }\end{array}$ & Pr > Diff & alpha (Modified) & $\begin{array}{c}\text { Signifi- } \\
\text { cant }\end{array}$
\end{tabular}} \\
\hline \multicolumn{7}{|c|}{\begin{tabular}{|l|l|l|l|l|l|l|} 
No.1 vs No.4 & 12.600 & 9.481 & 2.693 & $<0.0001$ & 0.050 & Yes
\end{tabular}} \\
\hline \multicolumn{7}{|l|}{ No.1 vs No.3 } \\
\hline \multicolumn{7}{|l|}{ No.1 vs No.2 } \\
\hline \multirow{2}{*}{$\begin{array}{l}\text { No.2 vs No.4 } \\
\text { No.2 vs No.3 }\end{array}$} & 2.200 & 1.655 & 2.444 & 0.236 & 0.050 & No \\
\hline & 0.900 & 0.677 & & & & No \\
\hline \begin{tabular}{|l|} 
No.3 vs No.4 \\
\end{tabular} & 1.300 & 0.978 & 2.334 & 0.334 & 0.025 & No \\
\hline
\end{tabular}

Tab. 13 Summary

\begin{tabular}{|c|c|c|c|c|}
\hline Category & LS means & Standard error & \multicolumn{2}{|c|}{ Groups } \\
\hline No.1 & 106.900 & 0.940 & A & \\
\hline No.2 & 96.500 & 0.940 & & B \\
\hline No.3 & 95.600 & 0.940 & & B \\
\hline No.4 & 94.300 & 0.940 & & B \\
\hline
\end{tabular}


Tab. 14 Sample / Dunnett (two sided) / Analysis of the differences between the control categories

\begin{tabular}{|c|c|c|c|c|c|c|}
\hline \multicolumn{7}{|c|}{ Sample / Dunnett (two sided) / Analysis of the differences between the control category } \\
\hline \multicolumn{7}{|c|}{ Sample-No.1 and the other categories with a confidence interval of $95 \%$ : } \\
\hline Contrast & Difference & Standardized difference & Critical value & Critical difference & Pr $>$ Diff & Significant \\
\hline No.1 vs No.4 & 12.600 & 9.481 & 2.452 & 3.259 & $<0.0001$ & Yes \\
\hline No.1 vs No.3 & 11.300 & 8.503 & 2.452 & 3.259 & $<0.0001$ & Yes \\
\hline No.1 vs No.2 & 10.400 & 7.826 & 2.452 & 3.259 & $<0.0001$ & Yes \\
\hline
\end{tabular}

Tab. 15 Summary of all pairwise comparisons

\begin{tabular}{|c|c|c|c|}
\hline \multicolumn{4}{|c|}{$\begin{array}{l}\text { Summary of all pairwise comparisons for Vzorek } \\
\text { (REGWQ): }\end{array}$} \\
\hline Category & LS means(Hardness HB) & \multicolumn{2}{|c|}{ Groups } \\
\hline No.1 & 106.900 & A & \\
\hline No.2 & 96.500 & & B \\
\hline No.3 & 95.600 & & B \\
\hline No.4 & 94.300 & & B \\
\hline
\end{tabular}

Tab. 16 Summary (LS means)

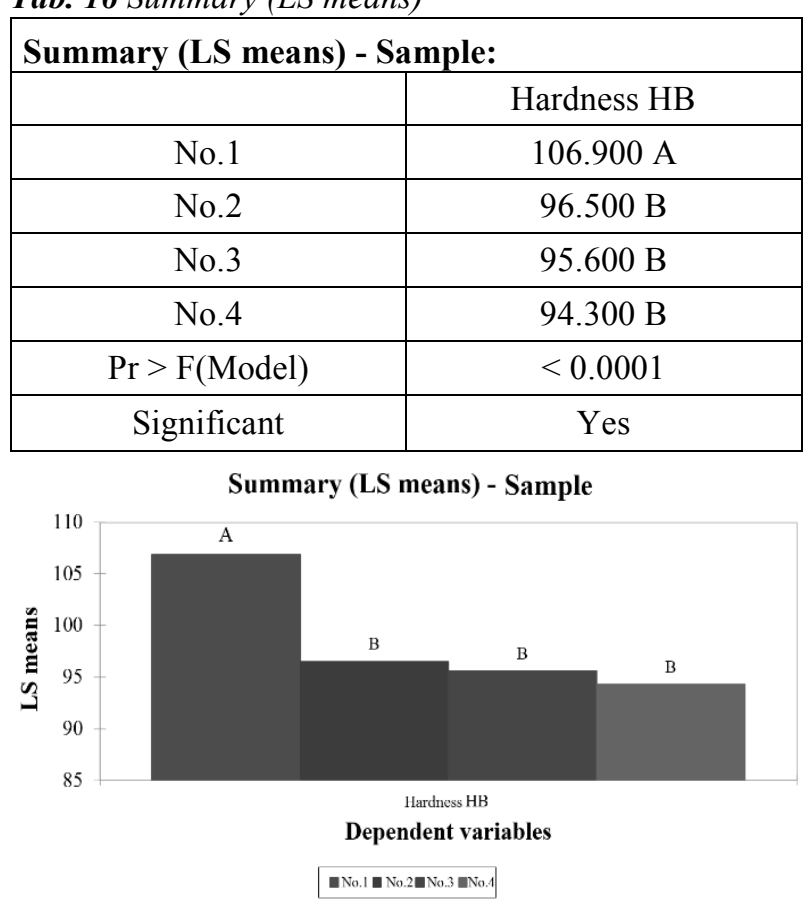

Fig. 14 Summary (LS means)

It is obvious from the Goodness of fit statistics test, that the determination coefficient $\mathrm{R} 2$ has a high value (R2 $=0.76$ ). It is indicating that $76 \%$ of the hardness variability can be explained by the sample type. The remaining $24 \%$ is due to a random error caused by other unrelated factors which not related to the addition of manganese.

From the ANOVA table, where the Fisher F test was used, it can be seen that the addition of manganese affects the hardness in the meaning, that the zero $\mathrm{H}_{0}$ hypothesis (the hypothesis, that the specimen type does not play a role in hardness measurement throughout the experiment) can be rejected. The error of the first type, the error that we reject wrongly with this zero hypothesis, is only $0.01 \%$. We can further claim that the hardness measurement throughout the experiment depends on the type of sample, with only $24 \%$ of the full explanation of hardness not affecting this type of sample.

From the model parameter table, we can see that all three samples with manganese content are very different from sample 1 without manganese as their $95 \%$ confidence intervals do not contain 0 . In the histogram describing the HB hardness, these results are visualized graphically - it is clear that the the confidence intervals do not cover the zero value for the manganese-free sample to which the analysis is performed.

From the Residue Table (Tab. 11), namely the Residue Column, we can see that more than $95 \%$ of the residue is in the range $(-1.96 ; 1.96)$, indicating that the ANOVA model is indeed normally distributed. There are only two outlying values for observation Obs9 $(-2.322)$ and observation Obs38 (-2.457). Everything is clearly visible from the relevant histogram (Standardized residuals / HB hardness, Fig. 11).

Tukey's HSD test is applied to all pairs. The three pairs (No.1, No.4) (No.1, No.3) (No.1, No.2) are significantly different, which means that the hardness depends primarily on whether the manganese is added or no. It does not matter the amount of manganese added. More specifically, there is no significant difference in hardness when 1, 2 or 3 wt. \% of manganese is added.

The REQWQ procedure shows that the three pairs (No.1, No.4) (No.1, No.3) (No.1, No.2) are significantly different, as a result of Tukey's HSD test. So we can divide the samples into two groups, the first one belongs to the sample No. 1 (ie without manganese) and the samples No. 2, No 3 and No 4 (ie with manganese) belong to the second group. This again signals the fact, that for the hardness it is only important to add or do not add manganese.

Dunnett's test confirms the results of the REQWQ procedure: just the three pairs (No.1, No.4), (No.1, No.3) (No.1, No.2) are significantly different.

\section{Conclusion}

The analysis performed on metallographic samples prepared from the AlSi12Fe6 alfinal bath in variants without the addition of $\mathrm{Mn}$, with the addition of $\mathrm{Mn}$ at a concentration of 1, 2 and 3 wt. \% clearly showed a significant change in the morphology of the excluded intermetallic phases due to the addition of manganese. The microstructures of all samples are eutectic. We can observe the elimination of needle-shaped intermetallic phases with high iron content $-\mathrm{Al}_{5} \mathrm{FeSi}$ in the microstructure of the alfination bath samples without the addition of manganese. The change in microstructure is already visible by 
the samples containing $1 \mathrm{wt} \%$ manganese. The microstructure contains the needle-shape formations of intermetallic phases with high iron content $-\mathrm{Al}_{5} \mathrm{FeSi}$ and the resulting poly-component intermetallic phases of the AlSi-Fe-Mn type. Samples containing 2 wt. \% and 3 wt. \% of manganese show almost complete conversion of microstructure from needle-shape intermetallic $\left(\mathrm{Al}_{5} \mathrm{FeSi}\right)$ formations to the globulitic-shape intermetallic phases on the basis of Al-Si-Fe-Mn.

The subsequent analyzes demonstrated the influence of manganese on the static tensile test and the Brinell hardness test. The sample without manganese added at a $55 \mathrm{MPa}$ load was $1.7 \%$ elongated, with an average hardness of 106.9 HB. Sample with manganese $1 \mathrm{wt}$. \% at a higher load of $110 \mathrm{MPa}$ achieved an extension of $1.8 \mathrm{wt}$. $\%$ at a lower average hardness of $96.5 \mathrm{HB}$. Sample with manganese addition $2 \mathrm{wt} . \%$ at a load of $110 \mathrm{MPa}$ reached an extension of 2 wt. \% and an average hardness of 95.6 HB. Sample with manganese addition 3 wt. $\%$ at a load of $110 \mathrm{MPa}$ reached an elongation of $2.2-2.6 \mathrm{wt}$. \% and average hardness $94.3 \mathrm{HB}$. Mutual comparison of the results showed that manganese samples increased the elongation and reduced hardness opposite to the manganesefree sample.

From statistical ANOVA: one factor is the effect of changing the mechanical properties by adding manganese in samples 2, 3, 4 to sample 1 not containing manganese. Applied multiple-pair comparison tests (Tukey HSD test) show that hardness depends primarily on whether manganese is added or not and does not matter the amount of manganese added. The total results made by one-way ANOVA are as follows:

Adding of manganese has a significant effect on increasing the hardness of the examined alloy and there is no significant difference in whether 1,2 or 3 wt. \% manganese. The experiment showed a significant effect of the addition of manganese to the alfinal bath of the AlSi12Fe6 alloy on the resulting alloy microstructure. However, the high iron content in the alloy does not allow significant improvement in mechanical properties. At the same time, the experiment was the basis for further research conducted at the Department of Technology and Materials Engineering aimed at eliminating the negative influence of iron in foundry Al-Si alloys.

\section{References}

[1] MAJERNIK, J., GASPAR, S., GRYC, K., SOCHA, L. (2018). Changes in Eutectic Silumin Structure Depending on Gate Geometry and Its Effect on Mechanical Properties of Casting. In Manufacturing Technology, Vol. 18, No. 3, pp. $439-443$.

[2] TILlOVÁ, E., CHALUPOVÁ, M., KUCHARIKOVÁ, L., BELAN, J., VAŠKO, A., ZÁVODSKÁ, D. (2017). Influence of Sr-Modification on Microstructure, Tensile, Impact and Hardness Properties of Secondary AlSi8Cu2Mn Cast Alloy. In Manufacturing Technology, Vol. 17, No. 6, pp. 972 - 978.

[3] KOVÁČIKOVÁ, P., VAVRO, J., VAVRO, J.jr., DUBEC, A. (2018). Microstructure Evaluation of Ductile Cast Iron and Numerical Modal Analysis. In Manufacturing Technology, Vol 18, No. 4, pp. 597 - 599.

[4] PODPROCKÁ, R., BOLIBRUCHOVÁ, D. (2018). The Role of Manganese in the Alloy Based on Al-Si-Mg with higher Iron Content. In Manufacturing Technology, Vol. 18, No. 4, pp. 650 654.

[5] BOLIBRUCHOVÁ, D., BRŮNA, M. (2017). Impact of the Elements Affecting the Negative IronBased Phases Morphology in Aluminium Alloys Summary Results. In Manufacturing Technology, Vol. 17, No. 5, pp. 675 - 679.

[6] HODINÁŘ, L., HREN, I., CAIS, J. (2017). Změna mikrostruktury alfinační lázně ze slitiny AlSi12Fe6 prostřednictvím prŕídavku manganu. Article Proceedings of 11th International Conference for Young Researchers and $\mathrm{PhD}$ students, Ústí nad Labem, pp. 300-308.

[7] MICHNA, Š., MICHNOVÁ, L. (2014). Neželezné kovy. FVTM, UJEP, Ústí nad Labem. 